Rec. Calomel.

Acid. arsenicosi tantidem.

Solv. in aq. dest. q. . ut addendo Gummi pulreratum wixturae pastae consistentiam accipiat.

Diese Präparate vernrsachen den Kranken veniger Schmerz als das Rousselotsche Pulver.

\title{
Neue Moxa.
}

Ferrari gibt an, Baumwolle in cine Aullösung ron chlorsaurem Kali zu tauchen und ihr die Gestalt kleiner Kegel zu geben, die man mehr oder weniger dicht und compakt machen kann. Diese Moxa ist kräftiger als die bisher geliannten von dem Gewebe der Blätter der Artemisia vulgaris, dem Mark von Helianthus tuberosus oder von Baumwolle, die man in Salpeterlösung getauch hat. (Journ. de Chim. med. IX 600.)

Teber cine Flüssigkeit, welche gegen Hantkrankheiten, Ausschläge, Kräıce u. s. w. angewandt wird

. 0

\section{La\&saigne.}

(Atuszug aus dem Journal de Chinie médicale, 1X. 5\%.)

Diese Flüssigheit war dcm Direktor der ThierarzneiSclule zu Alfort übersandt nit dem Ersuchen, über ihrs Wirksamlieit gegen Hautausschläge der Thiere Versucho anzustellen. 
Diese Flüssigheit bestand aus

$$
\begin{aligned}
& \text { salxsaurem lalk . . . 7,21 } \\
& \text { salzsaurem Mangan . . 25,79 } \\
& \text { Wasser . . . . . 67,00 } \\
& 100
\end{aligned}
$$

Eine derartige Flüssigkeit scheint bei der Darstellung des Chiors zur Fabrikation der Chlorüre, mittelst Manganoxyd und Salzsïure erhalten zu werden. Der Ueberschul's der Salzsüure wird ohne $Z$ weifel durçh Kreide gesättigt, proraus sich auch die Abwesenheit des Eisenoxydes in diesem Produbte erklären lälst. Ueber die Wirksamkeit dieses Mittels sind noch keine Erfuhrungen angegeben.

\section{Vierte Abtheilung. \\ L, it at ur und Kritik.}

Elemente der Krystallographie, nebst einer tabellurischen Uebersicht der Mineralien nach der hrystallform, vor: $G$ us $t$ a $v$ Rose. Mit 10 Kupjertafeln, Berlin 1883, bei Frnst Sicgfried Mittler.

Seit Ha uy, dem Gründer der ersten wissenscinaftlichen Betrachtung der Krystalle, fehlte es auch in Deutschland an tüchtigen Beförderern dieses interessanten Theils der Natur. geschichte nicht nur nicht, sondern wir wurden auch durch den Scharfsinn eines Bernhardi, Grassmann, Hessel, Mohs, Neumann, Naumann, Weil's a. a. dem Auslande darin überlegen.

Beruhardi, Mohs und Weils zeigten zuerst die Unzulänglichkeit der Ha uyschen Methode; letzterc beiden 